\title{
Termiticidal and Protozocidal Potentials of Eight Tropical Plant Extracts Evaluated Against Odontotermes obesus Rambur (Blattodea; Termitidae) and Heterotermes indicola Wasmann (Blattodea; Rhinotermitidae)
}

\author{
Asma Ashraf ${ }^{1}$, Naveeda Akhtar Qureshi ${ }^{1 *}$, Nargis Shaheen ${ }^{1}$, Attiya Iqbal', \\ Huma Fatima $^{1}$, Muhammad Afzal ${ }^{1}$, Saleh S. Alhewairini' ${ }^{2}$, Muhammad Zahid Qureshi ${ }^{3}$ \\ ${ }^{1}$ Department of Animal Sciences, Faculty of Biological Science, Quaid-i-Azam University Islamabad 45320, Pakistan \\ ${ }^{2}$ Department of Plant Production and Protection, College of Agriculture and Veterinary Medicine, \\ Qassim University, Saudi Arabia \\ ${ }^{3}$ Deanship of Educational Services, Science Unit, Department of Biochemistry, Qassim University, Saudi Arabia
}

Received: 24 July 2019

Accepted: 4 January 2020

\begin{abstract}
The subterranean termites Odontotermes obesus and Heterotermes indicola are highly infesting wood pests that cause economic losses that cost billions of dollars throughout the world - especially in tropical and subtropical regions. It is highly significant to formulate insecticides from plant-based chemicals rather than synthetic ones. The eight plant species resistant to termites were selected for screening as anti-termite phytochemicals. Extracts from different parts of the plants were collected by using ethanol solvents in different ratios. These extracts were evaluated for their toxicity against termites and their gut flagellates at subsequent concentrations in the range of $100-2000 \mathrm{ppm}$ to find $\mathrm{LC}_{50}$ Although the plants tested were found to be effective, extract from Grevillea robusta showed maximum mortality and reduced termite survival rate to $94 \%\left(\mathrm{LC}_{50}=1391.01\right)$ and $90 \%\left(\mathrm{LC}_{50}=1607.95\right)$ of $O$. obesus and $H$. indicola respectively. This extract also reduced the survival rate of hindgut flagellates of $H$. indicola up to $95 \%$ with an $\mathrm{LC}_{50}$ value of $502.64 \mathrm{ppm}$. The extract of Grevillea robusta was characterized by UV-Vis spectroscopy, FTIR and GC-MS analysis. Two absorption peaks were recorded by UV-Vis spectroscopy at 208.94 and $282.97 \mathrm{~nm}$ having absorption of 2.33 and 0.811 respectively. FTIR analysis confirmed the presence of amines, alcohols, alkanes, nitriles, aldehydes, ether and halo compounds. GC-MS analysis revealed the presence of 15 phytochemicals with a high percentage of Coumarin (30.64\%), 7-hydroxy, Methyl hexofuranoside (27.63\%) and 9,12,15-Octadecatrienoic acid
\end{abstract}

*e-mail: naveedaqresh@gmail.com 
$(\mathrm{Z}, \mathrm{Z}, \mathrm{Z})(8.97 \%)$. The natural phytochemicals from G. robusta having termiticidal and protozocidal potential being eco-friendly can replace synthetic pesticides for termite control.

Keywords: endosymbiont, termiticidal, Grevillea robusta, phytochemicals, spectroscopy, GC-MS

\section{Introduction}

Termites are "silent killers" as they ruin houses and wooden materials without showing external damage at initial stages. Globally, $90 \%$ of economic loss and $70 \%$ of construction damage is caused by the subterranean termites Coptotermes formosanus Shiraki and Coptotermes gestroi Wasmann [1-3]. Approximately \$1 billion is spent annually on the loss caused by termites in the United States [4]. In Southeast Asia, the cost of termite damage is approximately $\$ 400$ million per year [5]. Currently, a number of insecticides are available in the market, like carbamates, organochlorine, synthetic pyrethroids, chlordane, bifenthrin, fipronil and Termidor. Exposure to these synthetic insecticides causes serious health issues to humans, e.g., hyperglycemia, oxidative stress, and metabolic and nervous system disorders [6]. However, at the present time due to the lack of any effective alternative, these chemical insecticides are allowed for crop and soil treatments [7]. The urge for using naturally occurring botanical compounds as wood preservatives has increased from the last few decades [8-10]. Therefore, there is a need to explore natural products for developing pesticides or termiticides being biodegradable and environmentally friendly. Bioactive compounds from different plants that are cheaper, target-specific, biodegradable and non-toxic to humans can be used to replace synthetic insecticides [11]. Plant-derived biocides are naturally occurring compounds in roots, leaves, heartwood and bark, where they act as a defensive agent against xylophagous insects [12]. Termiticidal compounds like 2-methyl9,10-anthracenedione, 1-methyl-3,4-dihydroisoquinoline and squalene have been reported to be present in the heartwood of Tectona grandis [8]. Rasib et al. [13] reported that carboxylic acid isolated from Magnolia grandifolia and coniferyl alcohol from Saraca asoca were found to be a feeding deterrent against Odontotermes obesus. Similarly, a phytochemical "resorcinol" derived from Morus alba proved to be toxic against Reticulitermes flavipes [14].

Carica papaya (Caricaceae) is native to Mexico and northern South America. It is a medicinally important plant and is widely used as a whole plant as well as its seeds, leaves and fruits being used for pest control. $C$. papaya leaf extract exhibits antifungal, antibacterial, wound healing and antitumor potential [15]. The genus Eucalyptus (Myrtaceae) has more than 700 species native to Australia and is widely used as an antiseptic, repellent for insects, flavoring and fragrance agent, as well as in pharmaceuticals [16]. Antitermitic activity of Eucalyptus citriodora oil has been reported against higher termites and Heterotermes indicola [17] and antibacterial activity [18]. Antitermitic activities of E. camaldulensis leaf oil extract has been reported against Coptotermes formosanus in Thailand by both contact and fumigation methods [19]. The current study is based on the use of eight tropical plant leaf extracts for evaluating their termiticidal properties as they are locally available. The chemical characterization of the most effective plant was carried out by VU-Vis Spectroscopy, FTIR and GC-MS analysis. So that the natural plant products could become a good substitute for synthetic insecticides to prevent health hazards.

\section{Materials and Methods}

\section{Termite Collection}

Termite workers were collected from dead wooden logs and mud mounds using a collection of trap units prepared by plastic bottles containing wet toilet tissue rolls. Molasses was used as a phagostimulant to attract the termites. The traps were buried half underground at termite collection sites and monitored regularly. After 15 days, traps were brought to the laboratory, where active and healthy workers were separated. Live specimens were kept in Petri dishes with a soaked cotton plug in the laboratory at temperature $27 \pm 1^{\circ} \mathrm{C}$ and relative humidity $80 \pm 5 \%$. Termites were fed on No. 2 Whatman filter paper for one week, before the trail, to remove debris and other wood particles.

The plants leaves (Table 1 and Fig. 1) collected from the same vicinity were washed, shade dried at room temperature $\left(27-37^{\circ} \mathrm{C}\right)$ and powdered mechanically with an electric blender (Daigger Scientific, USA). Thirty grams of plant powder were subjected to obtain extract in $250 \mathrm{ml}$ of ethanol solvent by using a Soxhlet apparatus at $40-60^{\circ} \mathrm{C}$ (two cycles per hour) for 8 hours. The extract was concentrated by evaporating the solvent with a rotary vacuum evaporator (R-300, Rotavapor, Germany). The stock solution was prepared by dissolving $1 \mathrm{~g}$ of crude extract in $100 \mathrm{ml}$ of distilled water and different concentrations of 100, 500, 1000, 1500 and $2000 \mathrm{ppm}$ were prepared by applying formula $\mathrm{C}_{1} \mathrm{~V}_{1}=\mathrm{C}_{2} \mathrm{~V}_{2}$.

$$
V 1=\frac{\text { Required ppm } \times \text { Required Volume }}{\text { Stock Solution }}
$$

\section{Experimental Design}

No-choice bioassay [20] was designed to evaluate the toxic potential of plant extract against two species of termites: $O$. obesus and $H$. indicola. Whatman 
Table 1. Plants selected for antitermitic and antiprotozoan bioassays.

\begin{tabular}{|c|c|c|c|c|}
\hline Sr. No. & Botanical name & English name & Common name & Family \\
\hline 1 & Carica papaya & Papaya & Papita & Caricaceae \\
\hline 2 & Eucalyptus camaldulensis & River red gum & Safaida & Myrtaceae \\
\hline 3 & Ocimum basilicum & Sweet basil & Niazbo & Lamiaceae \\
\hline 4 & Grevillea robusta & Silky oak & Bahekar & Proteaceae \\
\hline 5 & Eucalyptus globules & Blue gum & Safaida & Myrtaceae \\
\hline 6 & Pongamia pinnata & Indian beech tree & Sukchain & Leguminosae \\
\hline 7 & Mentha longifolia & Horse mint & Podina & Lamiaceae \\
\hline 8 & Melia azedarach & Chinaberry tree & Dhraik & Meliaceae \\
\hline
\end{tabular}

No. 1 filter paper $(2.5 " \times 2.5$ ") was pre-weighed and treated with $1.5 \mathrm{ml}$ of different concentrations of (100, 500, 1000, 1500 and 2000ppm) for each plant extract. Papers were then air-dried at room temperature and kept in Petri dishes ( 3 " $\times 3$ "). Fifty termite workers of each species were placed in each petri dish containing plant extract-treated filter paper. The Petri dishes were kept in a dark environment at $27 \pm 1^{\circ} \mathrm{C}$ and $80 \pm 5 \mathrm{RH}$, and a few drops of distilled water were periodically added to each petri dish to keep up moisture content. All the experiments were conducted in replicates, and control was treated with distilled water only. Percentage mortality was calculated against each plant extract at every dose treatment after each $24 \mathrm{~h}$ for 16 days by applying the formula:

$$
\% \text { Mortality }=O D P \div T P \times 100
$$

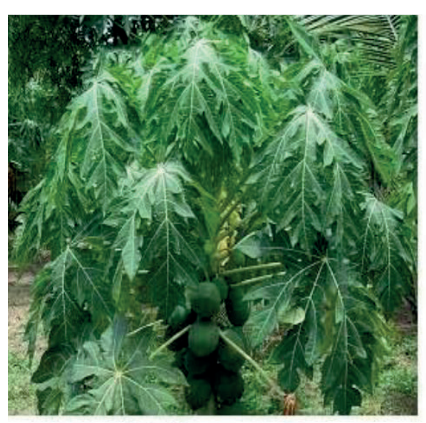

(a) C. papaya



(e) E. globulus

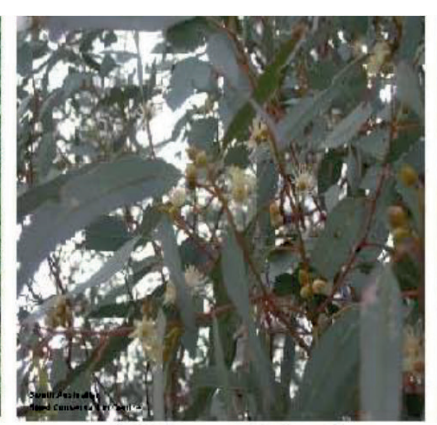

(b) E. camaldulensis

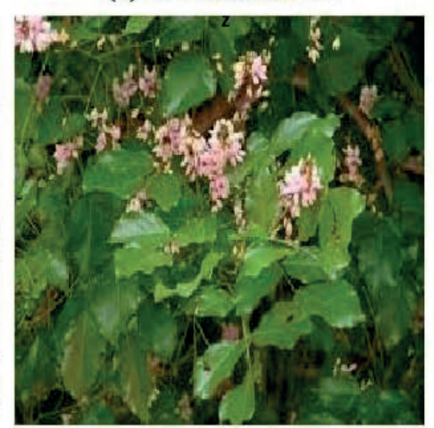

(f) P. pinnata

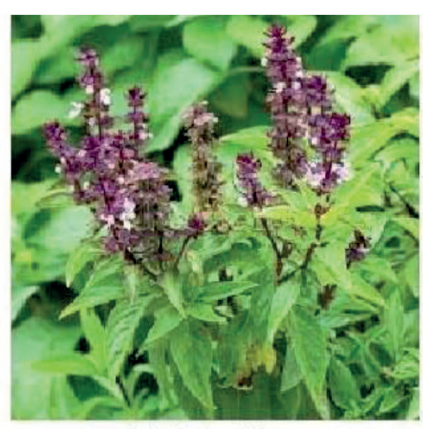

(c) O. basilicum

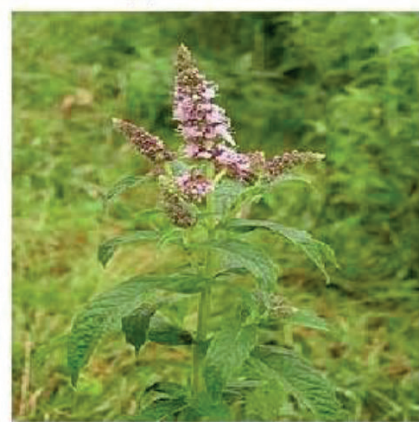

(g) M. longifolia

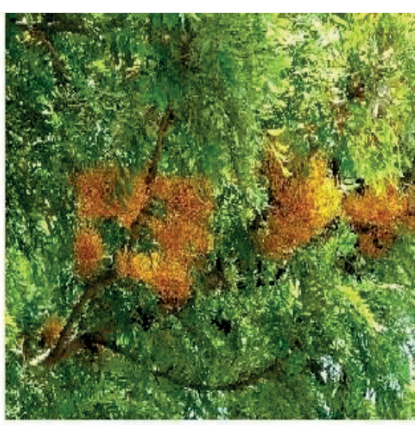

(d) G. robusta

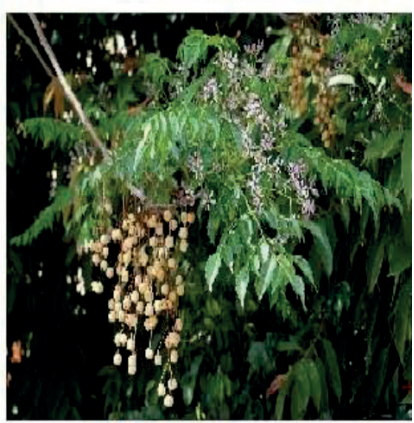

(h) M. azedarach

Fig. 1. Plants selected for antitermitic and antiprotozoan bioassays. 
(Optika B-500, Italia). Counts were made by calculating the mean number of protozoa in four squares of each chamber according to Lewis and Forschler [21], and results were compared with control for determining a decrease in the protozoa population.

$X=\frac{\left(\text { No. of cell counted } \times \text { Volume of saline } \frac{\text { solution }}{\text { sample }}\right)}{\left(\text { Volume of Neubar's chamber } \times \text { No. } \frac{\text { termites }}{\text { sample }}\right)}$

Characterization of the Most Effective Plant Extract

\section{UV-Vis Spectroscopy}

The leaf extract was examined under UV-Vis spectroscopic analysis for its spectral profile. The extract was centrifuged for 10 minutes at $3000 \mathrm{rpm}$ and filtered using Whatman No. 1 filter paper. The sample was then diluted 10 times with ethanol. The spectra were obtained by scanning the extract from 200 to $800 \mathrm{~nm}$ wavelength using a spectrophotometer (UV-1601, Shimadzu), and characteristic spectral peaks were recorded [22].

\section{Fourier Transform Infrared Spectroscopy (FTIR)}

Functional groups were detected by FTIR analysis and the characteristic peak values were recorded in the infrared region from 400-4000 $\mathrm{cm}^{-1}$ [23]. The sample was prepared by mixing $2 \mathrm{mg}$ of leaf extract in $100 \mathrm{mg}$ of $\mathrm{KBr}$ (FTIR grade). The mixture was then compressed to prepare $3 \mathrm{~mm}$ (diameter) salt discs which were loaded in FTIR spectroscopy (Shimadzu ETIR spectrophotometer) and scanned to record infrared spectra at different wavelengths $\left(400-4000 \mathrm{~cm}^{-1}\right)$.

\section{Gas Chromatograph-Coupled Mass Spectroscopy $(G C-M S)$}

Leaf extract was further analyzed by using gas chromatography coupled with a mass spectrophotometer (GC-2010, Shimadzu). The chromatographic system was installed with an AOC-20i auto-injector, AOC20s autosampler and QP2010 mass selective detector. The fused silica capillary column (DB-5Ms, $0.25 \mathrm{~mm} \times 30 \mu \mathrm{m} \times 0.25 \mu \mathrm{m})$ having a maximum temperature capacity of $325^{\circ} \mathrm{C}$ was used for screening. The column's initial temperature was $100^{\circ} \mathrm{C}$ and maintained at this temperature for 0.5 minutes. The temperature of the oven was then increased to $280^{\circ} \mathrm{C}$ $\left(24^{\circ} \mathrm{C} / \mathrm{min}\right)$ and maintained for 3 minutes. Injector temperature was $250^{\circ} \mathrm{C}$ with a flow rate of Helium as $1.0 \mathrm{ml} / \mathrm{min}$. The chromatograph was operated in split injection mode with an injection volume of $1.0 \mu \mathrm{L}$ and split ratio of 10:1. The ionization voltage was $70 \mathrm{eV}$ and the mass spectral scan range was $50-350 \mathrm{~m} / \mathrm{z}$.

\section{Identification of Phytoconstituents}

The National Institute of Standards and Technology (NIST) database having more than 62000 patterns was used for interpreting the mass spectrum. The

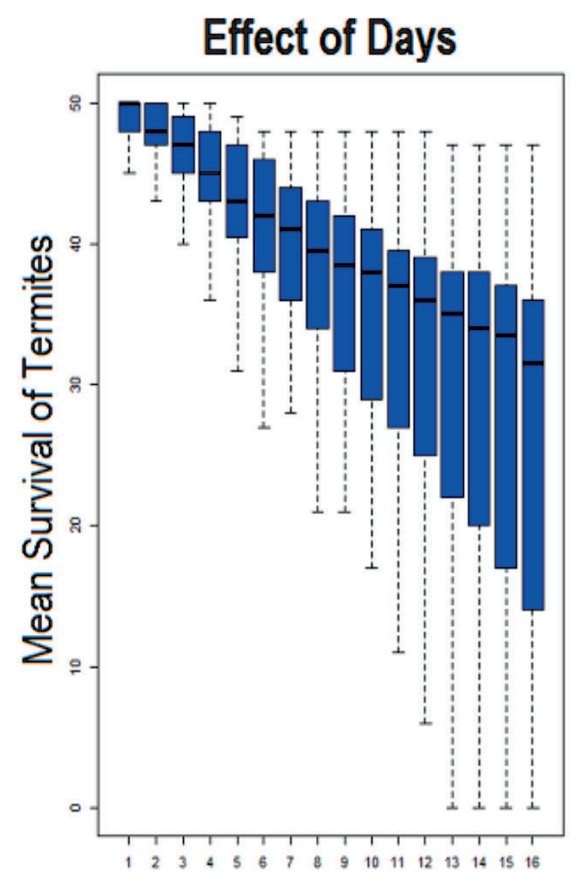

Days

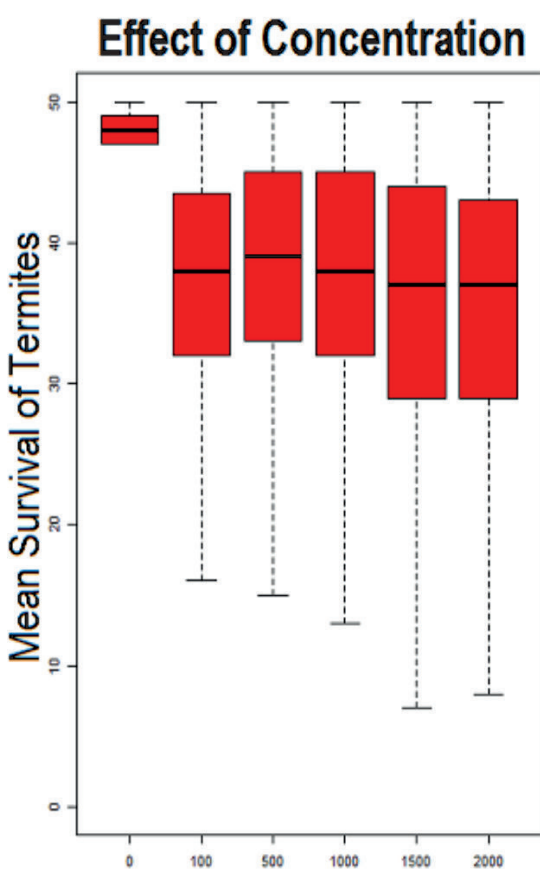

Concentration (ppm)



Plants

Fig. 2. Box plot representing the effect of days, concentration and plants on the mean survival of $O$. obesus. 
comparison between spectra of known and unknown compounds, from the NIST library, helps in interpreting the mass spectrum and determining name, chemical formula, chemical structure and molecular weight of identified compounds [24].

\section{Statistical Analysis}

Mean mortality of termites and protozoa for each plant extract and concentration was compared, and statistically significant differences were determined using one-way ANOVA with Tukey's multiple comparison tests using "R language". Results with $\mathrm{P}$ value less than 0.05 were considered to be significant and less than 0.005 considered strongly significant. Stars $(*, * *, * * *)$ denote statistically significant differences at $\mathrm{p} \leq 0.05, \mathrm{p} \leq 0.01$ and $\mathrm{p} \leq 0.001$, respectively. $\mathrm{LC}_{50}$ value of each plant extract against termites and their gut protozoa was calculated by applying "probit analysis" using SPSS software version 19.

\section{Results and Discussion}

\section{Antitermitic Activity of Plant Extract Against $O$. obesus and $H$. indicola}

Antitermitic activity of ethanolic leaf extract of eight plants against two termite species (O. obesus and $H$. indicola) was evaluated by using a no-choice bioassay. Five different concentrations (100, 500, 1000, 1500 and 2000) were used in a 16-day experiment, and the mean survival of termites was calculated. All concentrations were found to have a significant effect on termite survival against $O$. obesus as compared to control $(F(d f)=289.0(5) ; \mathrm{P}<0.05)$ in a time-dependent manner, which also differed significantly from each other $(F(d f)=216.0(16) ; \mathrm{P}<0.05)$. Similarly, all plants showed different antitermitic activity in dose- and time-dependent manners $(F(d f)=209.6$ (8); $\mathrm{P}<0.05)$. The effects of days, concentrations and plants on mean survival of termites is represented in Fig. 2. Among the tested plants, G. robusta was found to be most effective, with a significant $(\mathrm{P}<0.05)$ reduction in survival of termites $(94 \%)$ at the $16^{\text {th }}$ day of the experiment. Similarly, O. basilicum, E. camaldulensis and E. globulus also significantly $(\mathrm{P}<0.05)$ reduced termite populations with 34,40 and $60 \%$ survival rate, respectively. However, M. azedarach, C. papaya, $M$. longifolia and $P$. pinnata have a non-significant effect on termite survival with less than $30 \%$ reduction in the termite population (Fig. 3).

An almost similar response was observed against the mean survival of $H$. indicola in O. obesus. All concentrations were found to have a significant effect on termite survival as compared to control $(F \quad(d f)=343.0(5) ; \quad \mathrm{P}<0.05)$ in a time-dependent manner, that also differed significantly from each other $(F(d f)=261.6(16) ; \mathrm{P}<0.05)$. Similarly, all plants showed differential antitermitic activity in dose- and time-dependent manners $(F(d f)=234.8$ (8); $\mathrm{P}<0.05)$. The effect of days, concentrations and plants on mean survival of termites is represented in Fig. 4. Among all plants used, G. robusta showed a significant $(\mathrm{p}<0.05)$ decrease in the termite population with $50 \%$ termite death after the $10^{\text {th }}$ day of the experiment. About $90 \%$ of termite mortality was recorded on the $16^{\text {th }}$ day of the experiment. Similarly, E. camaldulensis, O. basilicum,

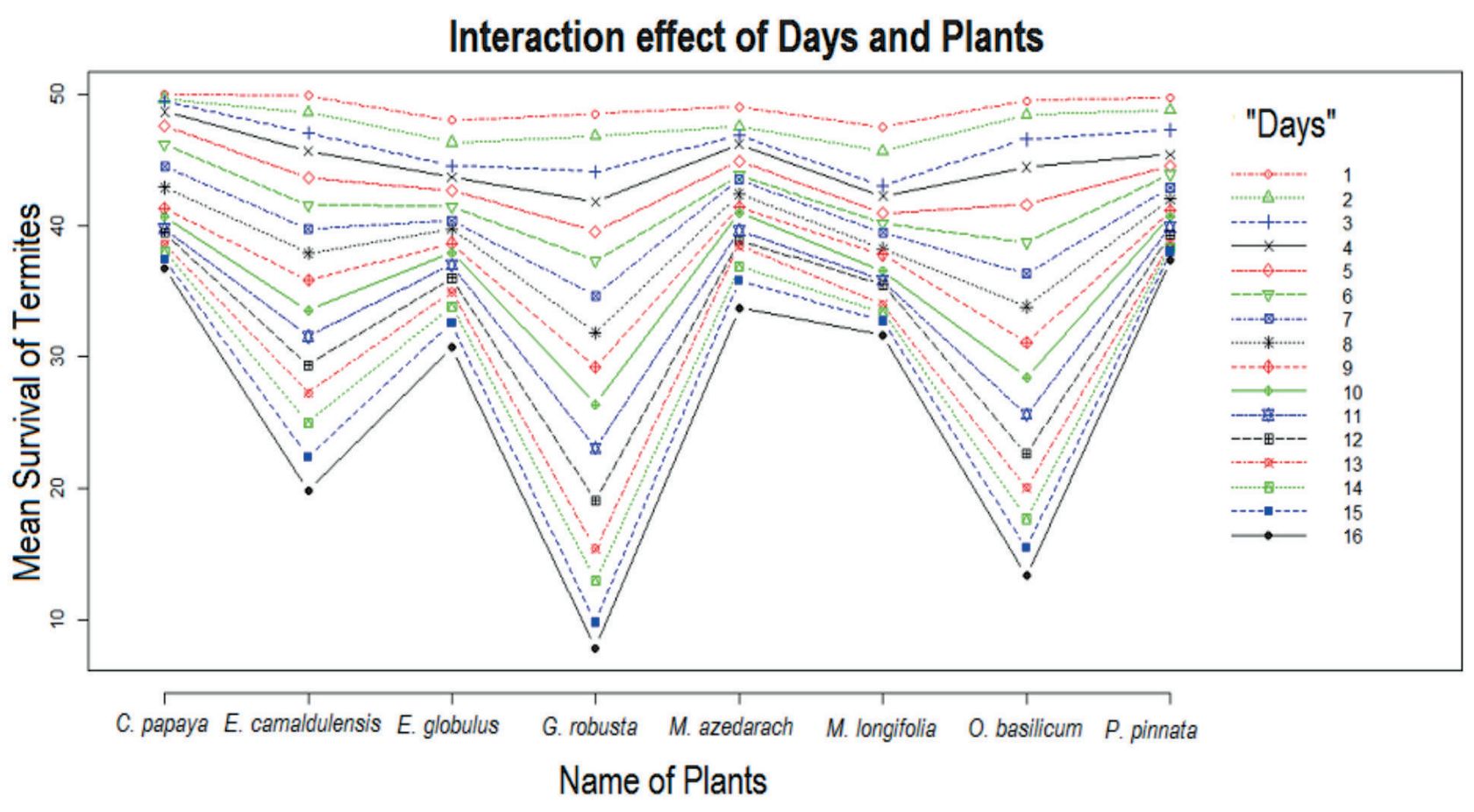

Fig. 3. Interaction plot representing the interaction effect of plant extract with days on mean survival of $O$. obesus. 



Fig. 4. Box plot representing the effect of days, concentration and plants on the mean survival of $H$. indicola.

E. globulus and M. azedarach were also found to have a significant $(\mathrm{p}<0.05)$ effect on termite survival and reduced their populations by up to $70,65,59$ and $54 \%$, respectively. However, C. papaya, M. longifolia and $P$. pinnata have a non-significant effect on termite survival with less than $30 \%$ reduction in the termite population (Fig. 5). Calculated $\mathrm{LC}_{50}$ values of all plants are represented in Table 4. The level of significance of all the plants and their comparative analysis between each other is represented in Tables 2 and 3.

For the control of termites, synthetic insecticides have been used from the last few decades that have resulted in insecticidal resistance, human health disorders, and

\section{Interaction effect of Days and Plants}

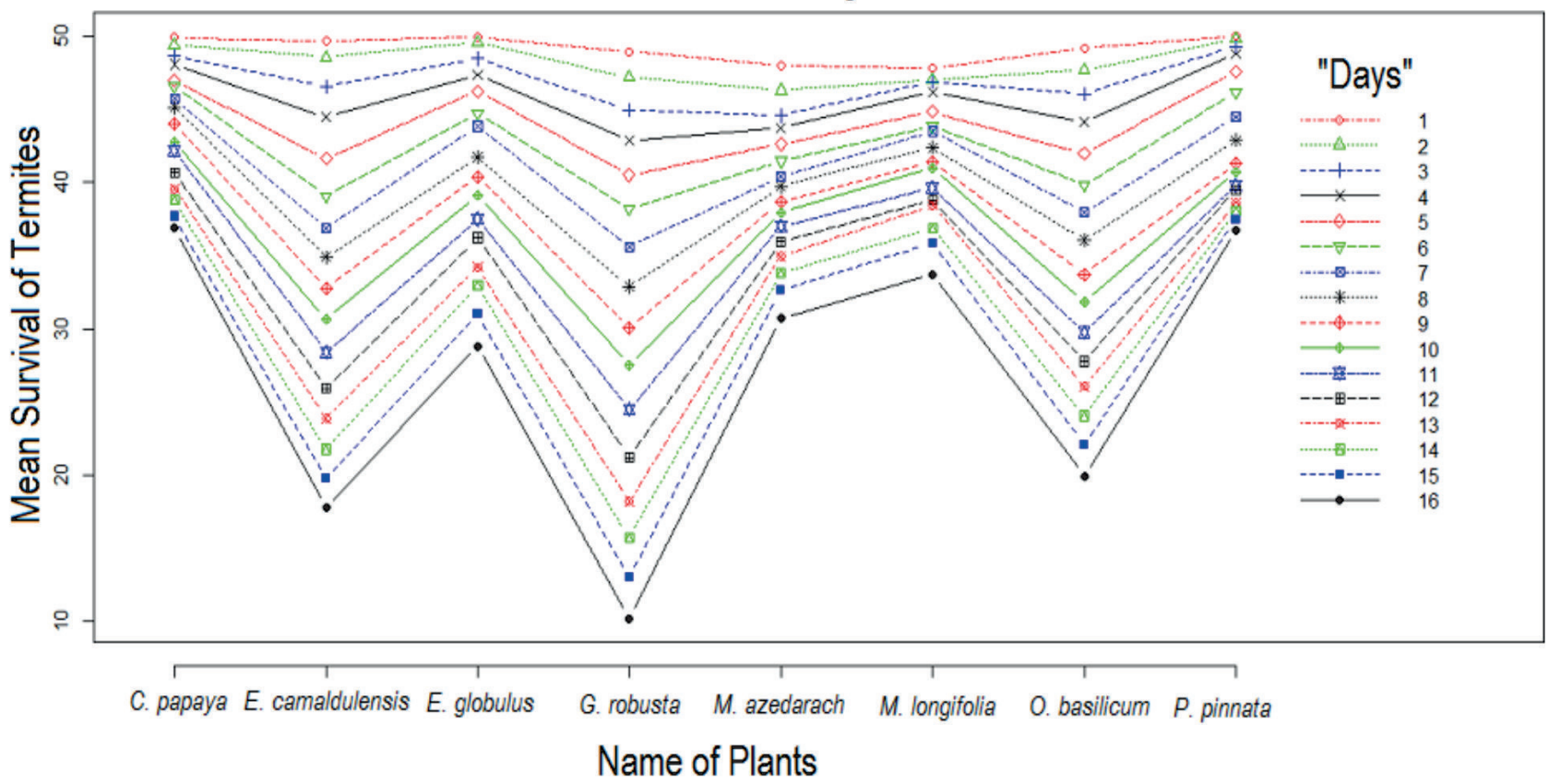

Fig. 5. Interaction plot representing the interaction effect of plants extract with days on mean survival of $H$. indicola. 
Table 2. Comparative significance analysis of plants used for antitermitic activity against $O$. obesus, $H$. indicola and its hindgut Protozoa.

\begin{tabular}{|c|c|c|c|}
\hline \multirow{2}{*}{ Plants Name } & \multicolumn{3}{|c|}{ Level of Significance } \\
\cline { 2 - 4 } & O. obesus & H. indicola & Protozocidal \\
\hline C. papaya & Non-Significant & Non-Significant & Significant***ant*** \\
\hline E. camaldulensis & Significant** & Significant** & Significant** \\
\hline E. globulus & Significant* & Significant* & Significant*** \\
\hline G. robusta & Significant*** & Significant*** & Non-Significant \\
\hline M. azedarach & Non-Significant & Significant* & Significant* \\
\hline M. longifolia & Non-Significant & Non-Significant & Significant*** \\
\hline O. basilicum & Significant*** & Significant** & Non-Significant \\
\hline P. pinnata & Non-Significant & Non-Significant & \\
\hline
\end{tabular}

Table 3. Comparison of significance level $(\mathrm{P}<0.05)$ between plants used for antitermitic activity against O. obesus, H. indicola and its hindgut Protozoa.

\begin{tabular}{|c|c|c|c|c|c|c|}
\hline \multirow{2}{*}{ Plant Name } & \multicolumn{2}{|l|}{ O. obesus } & \multicolumn{2}{|l|}{ H. indicola } & \multicolumn{2}{|l|}{ Protozocidal } \\
\hline & Level of Significance & $P$ value & Level of Significance & $P$ value & Level of Significance & $P$ value \\
\hline C. papaya - E. camaldulensis & Significant & 0.000 & Significant & 0.000 & Significant & 0.000 \\
\hline C. papaya - E. globulus & Significant & 0.000 & Significant & 0.000 & Significant & 0.000 \\
\hline C. papaya - G. robusta & Significant & 0.000 & Significant & 0.000 & Significant & 0.000 \\
\hline C. papaya - M. azedarach & Non-Significant & 0.129 & Significant & 0.000 & Significant & 0.000 \\
\hline C. papaya - M. longifolia & Significant & 0.000 & Significant & 0.000 & Significant & 0.000 \\
\hline C. papaya-O. basilicum & Significant & 0.000 & Significant & 0.000 & Significant & 0.000 \\
\hline C. papaya - P. pinnata & Non-Significant & 0.698 & Non-Significant & 0.720 & Significant & 0.000 \\
\hline E. camaldulensis - E. globulus & Significant & 0.000 & Significant & 0.000 & Significant & 0.000 \\
\hline E. camaldulensis - G. robusta & Significant & 0.000 & Significant & 0.000 & Non-Significant & 0.204 \\
\hline E. camaldulensis - M. azedarach & Significant & 0.000 & Significant & 0.000 & Significant & 0.000 \\
\hline E. camaldulensis - M. longifolia & Significant & 0.000 & Significant & 0.000 & Significant & 0.000 \\
\hline E. camaldulensis - O. basilicum & Significant & 0.000 & Non-Significant & 0.378 & Non-Significant & 0.996 \\
\hline E. camaldulensis - $P$. pinnata & Significant & 0.000 & Significant & 0.000 & Significant & 0.000 \\
\hline E. globulus - G. robusta & Significant & 0.000 & Significant & 0.000 & Significant & 0.000 \\
\hline E. globulus - M. azedarach & Significant & 0.000 & Non-Significant & 0.020 & Significant & 0.000 \\
\hline E. globulus - M. longifolia & Non-Significant & 0.641 & Non-Significant & 0.317 & Significant & 0.000 \\
\hline E. globulus - O. basilicum & Significant & 0.000 & Significant & 0.000 & Significant & 0.000 \\
\hline E. globulus - P. pinnata & Significant & 0.000 & Significant & 0.000 & Significant & 0.000 \\
\hline G. robusta - M. azedarach & Significant & 0.000 & Significant & 0.000 & Significant & 0.000 \\
\hline G. robusta $-M$. longifolia & Significant & 0.000 & Significant & 0.000 & Significant & 0.000 \\
\hline G. robusta - O. basilicum- & Significant & 0.000 & Significant & 0.000 & Non-Significant & 0.030 \\
\hline G. robusta $-P$. pinnata & Significant & 0.000 & Significant & 0.000 & Significant & 0.000 \\
\hline M. azedarach - M. longifolia & Significant & 0.000 & Significant & 0.000 & Non-Significant & 0.246 \\
\hline M. azedarach-O. basilicum & Significant & 0.000 & Significant & 0.000 & Significant & 0.000 \\
\hline M. azedarach - P. pinnata & Non-Significant & 0.974 & Significant & 0.000 & Non-Significant & 0.197 \\
\hline M. longifolia - O. basilicum & Significant & 0.000 & Significant & 0.000 & Significant & 0.000 \\
\hline M. longifolia - $P$. pinnata & Significant & 0.000 & Non-Significant & 0.027 & Significant & 0.000 \\
\hline
\end{tabular}


Table 4. $\mathrm{LC}_{50}$ values of plants used for antitermitic activity against $O$. obesus, H. indicola and its hindgut Protozoa.

\begin{tabular}{|c|c|c|c|}
\hline \multirow{2}{*}{ Plants Name } & \multicolumn{3}{|c|}{ LC $_{50}(\mathrm{ppm})$} \\
& Opper confidence limit - Lower confidence limit \\
\cline { 2 - 4 } & $6329.70(7478.71-5519.87)$ & $3546.81(3776.76-3350.46)$ & $1046.24(1052.65-1039.86)$ \\
\hline C. papaya & $2973.69(3231.45-2762.92)$ & $2214(2351.38-2097.04)$ & $594.70(601.77-588.29)$ \\
\hline E. camaldulensis & $3148(3375.31-2957.11)$ & $2754.81(2889.69-2635.82)$ & $1373.28(1380.49-1366.13)$ \\
\hline E. globulus & $1391.01(1455.08-1331.88)$ & $1607(1686.03-1537.49)$ & $502.64(506.97-497.10)$ \\
\hline G. robusta & $5308.70(6093-78-4726.97)$ & $3154.99(3383.57-2962.57)$ & $2475.97(2498.83-2453.83)$ \\
\hline M. azedarach & $9408.11(14283.4-7124.08)$ & $5395.08(6220.86-4788.18)$ & $3093.47(3129.35-3058.63)$ \\
\hline M. longifolia & $1926(2039.53-1827.68)$ & $2515.19(6220.86-4788.18)$ & $683.60(688.63-678.56)$ \\
\hline O. basilicum & $5468.71(6293.14-4860.36)$ & $6240.51(7348.15-5455.17)$ & $2080.22(2096.91-2063.87)$ \\
\hline P. pinnata & &
\end{tabular}

environmental issues. So the replacement of synthetic insecticides with bio-pesticides is strongly required as they are a rich source of bioactive compounds and less toxic [25]. In the past, many studies have been conducted to evaluate the toxic effects of plants on termites and their hindgut endosymbionts. Abbas et al. [26] reported the antitermitic activity of 15 medicinal plants, including Ricinus communis, Croton tiglium, Ocimum basilicum, Psoralea corylifola, Nigella sativum, Mentha sp., Cichorium intybus, Peganum harmala, Foeniculum vulgare, Allium sativum, Plantago ovate, Moringa oleifera, Capsicum frutescens, Melia azedarach and Azadirachta indica against $O$. obesus, and found that O. basilicum, P. harmala and $F$. vulgare have potential to be used as antitermitic agents. These plants have many bioactive constituents that can be used against termites. In previous studies, the leaf and seed extracts of Jatropha curcas, bark extract of Melia azedarach, rhizome extract of Curcuma longa, leaf extract of Nerium indicumi and crude seed extract of Annona were evaluated for behavioral, feeding and tunneling activities of subterranean termites [27]. Similarly the effect of crude extracts of Azadirachta indica, Pyllanthus niruri, Andrographis paniculata and Leucaena leucocephala on behavior and feeding activities was studies against Coptotermes gestroi and Globitermes sulphurues [28].

In the present study among the tested eight plant species, G. robusta was found to have promising activity and cause significant $(\mathrm{P}<0.05)$ reduction in termite survival. About $50 \%$ termite death was recorded on the $10^{\text {th }}$ day of the experiment, with a survival rate of 6 and $10 \%$ (94 and $90 \%$ mortality) on the $16^{\text {th }}$ day of the experiment in both termite species, i.e., O. obesus and H. indicola.

E. camaldulensis and $O$. basilicum were also reported to have a significant $(\mathrm{P}<0.05)$ effect on termite survival and reduce up to 70 and $65 \% \mathrm{H}$. indicola population, but they do not differ significantly from each other $(\mathrm{P}=0.378)$. However, in the case of O. obesus, $O$. basilicum was found to be more effective than $E$. camaldulensis and caused 76 and $60 \%$ reduction in the termite population. Similarly, E. globulus and $M$. azedarach were also active significantly $(\mathrm{P}<0.05)$ against termites, but have non-significant $(\mathrm{P}=0.20)$ differences among each other. The results of the present study are comparable with a recent study conducted by Hassan et al. [14] showing that the population of Reticulitermes flavipus was reduced significantly when exposed to the extracts of Morus alba, and we found that the percentage mortality of termites was concentration-dependent. The activity profile of all tested plants against $O$. obesus is as follows; G. robusta $>O$. basilicum $>E$. camaldulensis $>$ E. globulus $>M$. longifolia $>M$. azedarach $>C$. papaya $>$ $P$. pinnata. Similarly, the activity profile of all tested plants against $H$. indicola is as follows: $G$. robusta> E. camaldulensis $>O$. basilicum $>E$. globulus $>M$. azedarach $>$ M. longifolia $>C$. papaya $>P$. pinnata.

\section{Protozocidal Activity of Plant Extract}

Protozocidal activity of the above-mentioned eight plants were also calculated against the mean survival of the protozoa population isolated from the hindgut of $H$. indicola. All concentrations were found to have a significant effect on protozoa survival as compared to control $(F(d f)=553.5(5) ; \mathrm{P}<0.05)$ in a timedependent manner, which also differed significantly from each other $(F(d f)=177.2(7) ; \mathrm{P}<0.05)$. Similarly, all plants showed differential protozocidal activity in dose- and time-dependent manners $(F(d f)=141.3(8)$; $\mathrm{P}<0.05)$. The effect of days, concentration and plants on the mean survival of the protozoa population is represented in Fig. 6. Among all the plants, G. robusta, $E$. camaldulensis and $O$. basilicum were found to be most effective and have a significant $(\mathrm{P}<0.05)$ effect on survival of protozoa with 95,78 , and $74 \%$ reduction in the population on the $16^{\text {th }}$ day of the experiment. Similarly, C. papaya, E. globulus and M. longifolia also significantly $(\mathrm{P}<0.05)$ reduced the protozoa population with 66, 56 and 46\% mortality respectively. However, $M$. azedarach and $P$. pinnata have a non-significant 


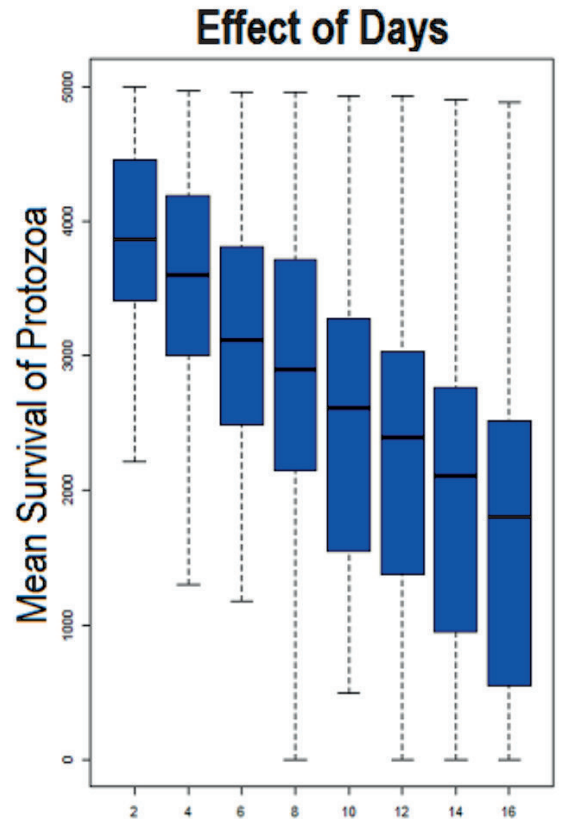

Days


Fig. 6. Box plot representing the effect of days, concentration and plants on the mean survival of protozoa isolated from the hindgut of H. indicola.

effect on the protozoa population (Fig. 7). Calculated $\mathrm{LC}_{50}$ values of all plants are represented in Table 4. The level of significance of all the plants and their comparative analysis between each other is represented in Tables 2 and 3.
Protozocidal activity by feeding on extracttreated filter papers was also investigated against the endosymbiotic flagellate population of $H$. indicola. In previous studies, the toxic potential of some natural products against hindgut flagellates has been

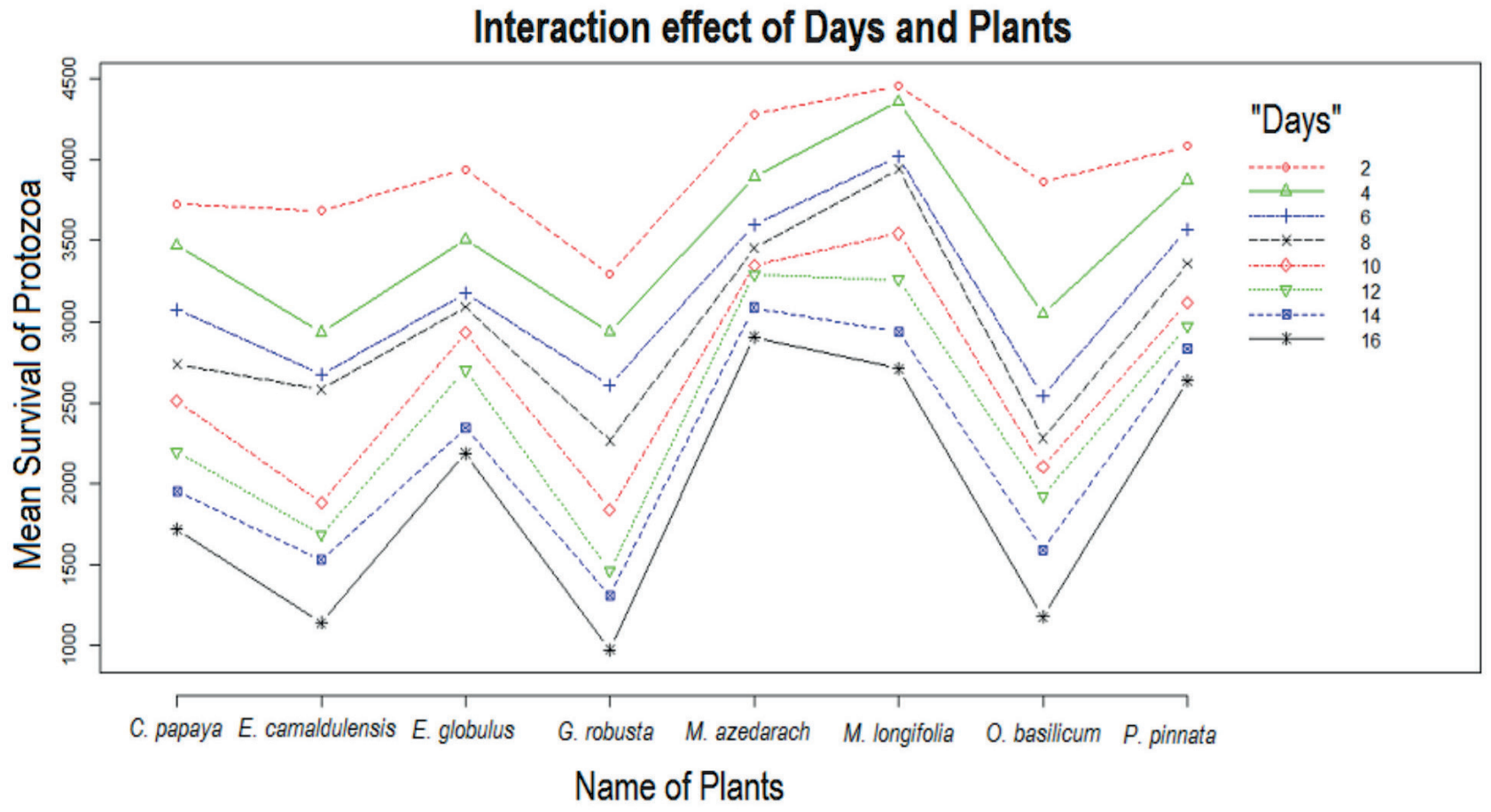

Fig. 7. Interaction plot representing the interaction effect of plant extracts with days on mean survival of protozoa isolated from the hindgut of $H$. indicola. 
reported. One study, conducted by Doolittle and his coworkers [29], used bioactive compounds from neem extract, gleditschia from Gleditschia triacanthas and capsaicin from cayenne pepper (Capsicum sp.) against endosymbiotic fauna of Formosanus subterranean termites, and evaluated that neembokil was more significant for decreasing the population of $P$. grassii and spirochaete genus. Similarly, the comparative effect of synthetic disodium octaborate tetrahydrate with natural vetiver oil and nootkatone on endosymbionts to C. formosanus was conducted in the laboratory trials for 12 months [30]. In choice and no-choice bioassays it was revealed that nootkatone and vetiver oil had a more significant $(\mathrm{P} \leq 0.05)$ effect on termite hindgut flagellates than disodium octaborate tetrahydrate.

In the present study, leaf extract of eight plants was evaluated against protozoan fauna of $H$. indicola and found that all plants have differential protozocidal activity in a dose-dependent manner with an increase in time. G. robusta, O. basilicum and E. camaldulensis showed high activity profile and caused significant $(\mathrm{P}<0.05)$ elimination of protozoan fauna from termite hindgut. However, they have non-significant differences among each other, i.e., G. robusta and E. camaldulensis $(\mathrm{P}=0.204), G$. robusta and $O$. basilicum $(\mathrm{P}=0.030)$, and E. camaldulensis and $O$. basilicum $(\mathrm{P}=0.996)$. These results are compatible with a study conducted by Afzal et al. [31], who concluded that a reduction in the protozoa population was directly related to the filter paper area consumption treated with plant extract and found that after two weeks of exposure of termites to treated filter paper in no-choice bioassay at the concentration of $20 \mathrm{mg} / \mathrm{ml}$ of plant leaf extract reduced the protozoa population by $62.90 \%$ as compared to the untreated negative control. Similarly, C. papaya, E. globulus and $M$. longifolia infected protozoan populations significantly $(\mathrm{P}<0.05)$ and caused a decline in their survival of up to 66,56 and $46 \%$ respectively. However, the termite survival rate was high in those experimental units where filter papers were treated with extract of these plants. The present findings are comparable with the study conducted by Hassan et al. [14] on protozoan fauna of Reticulitermes flavipus, who reported that heartwood extracts of Morus alba at its highest concentration $(10 \mathrm{mg} / \mathrm{ml})$ reduced the protozoan population by up to $50 \%$, but the survival rate of termites was $7 \%$. So while it is recommended that termite mortality is not only the result of the decline in protozoan population, many other physiological phenomenon may also affect their survival during continuous exposure to plant extract [32]. Similarly, in the present study, a decline in the protozoan population was higher in treated termites, but their survival rate was also high, suggesting that the plant extract might have some other mode of action that causes termite mortality (Figs 5 and 7). The protozoa population was declined totally in termite hindgut when exposed to toxic compounds that eventually led to termite death. The activity profile of all tested plants against protozoa was as follows: G. robusta $>E$. camaldulensis $>O$. basilicum $>$ C. papaya $>E$. globulus $>M$. longifolia $>P$. pinnata $>$ M. azedarach.

\section{Characterization of Most Effective Plants}

\section{UV-Vis Spectroscopy}

Qualitative UV-Vis spectroscopic analysis of $G$. robusta leaves extract in ethanol solvent showed a spectrum profile at 200 to $800 \mathrm{~nm}$ due to the sharpness of peaks and proper baseline. The peak spectra of G. robusta showed characteristic peaks at 208.94 and $282.97 \mathrm{~nm}$ with the absorption of 2.33 and 0.811 respectively (Fig. 8).

\section{Fourier Transform Infrared Spectroscopy} (FTIR)

Functional groups of active compounds in ethanolic leaf extract of G. robusta were identified using FTIR analysis. Each peak in the spectrum represents the specific peak value corresponding to the specific functional group. The absorbance was noted from 400 to $4000 \mathrm{~cm}^{-1}$ wavelength. The results of FTIR analysis confirmed the presence of amines, alcohol, alkanes, nitriles, aldehyde, ether, and halo compounds (Table 5 and Fig. 9).

\section{Gas Chromatograph-Coupled Mass Spectroscopy (GC-MS)}

Gas chromatograph-coupled mass spectroscopy (GC-MS) of ethanolic leaf extracts of G. robusta indicated 15 peaks, which revealed the presence of 15 phytochemical compounds. The mass spectrum of each compound was characterized by comparison with the NIST library. Compound name, retention time, area percentage, molecular weight and a molecular formula

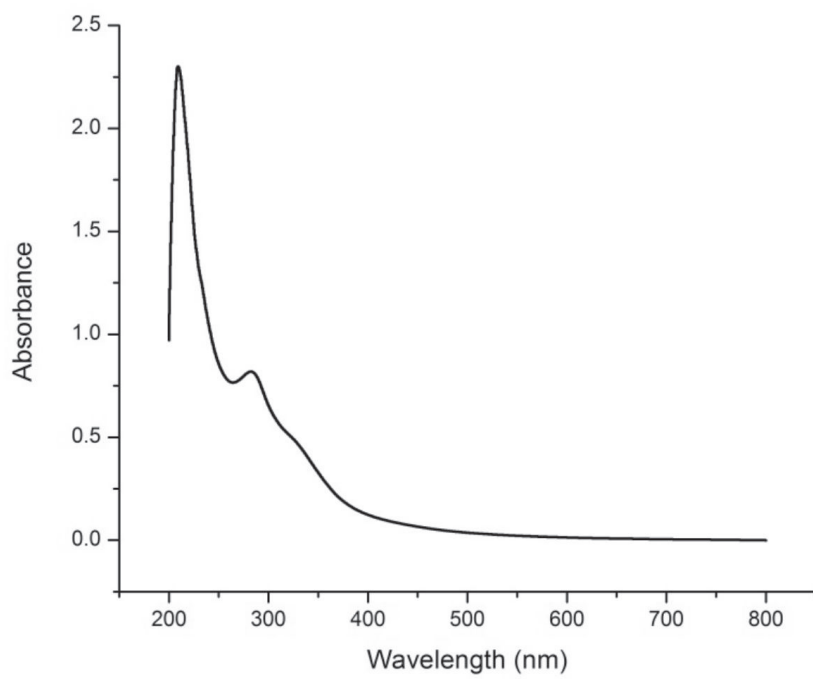

Fig. 8. UV-Vis spectra of ethanolic leaf extract of G. robusta. 
Table 5. FTIR spectral peak values and functional groups obtained from ethanolic leaf extract of G. robusta.

\begin{tabular}{|c|c|c|c|}
\hline Peak \# & Peak Value & Type of stretching & Functional group \\
\hline 1 & 3307.00 & N-H stretch/O-H stretch & Alkane \\
\hline 2 & 2976.32 & C-H stretch & Nitriles \\
\hline 3 & 2943.98 & C $\equiv \mathrm{N}$ & Aldehyde \\
\hline 4 & 2831.48 & C-H stretch & Alkane \\
\hline 5 & 1488.88 & C-H bending & Ether/Alcohol \\
\hline 6 & 1088.70 & C-O stretch & Amines \\
\hline 7 & 1023.33 & C-N stretch & Halo compound \\
\hline 8 & 880.88 & C-H bending & Halo compound \\
\hline 9 & 630.24 & C-X stretch & Halo compound \\
\hline 10 & 542.66 & C-X stretch & Halo compound \\
\hline 11 & 527.03 & C-X stretch & C-X stretch \\
\hline 12 & 522.55 & & \\
\hline
\end{tabular}

of identified components are listed in Table 6. The GC-MS chromatograms of identified compounds are presented in Fig. 10.

Extraction and analysis of natural bioactive compounds from the medicinal plants help in quality control of herbal medicines and their use to secure human beings and other animals from an attack of natural toxins [33]. Therefore, in the present study characterization of a most effective plant ( $G$. robusta) was carried out using VU-Vis spectroscopy, FTIR and GC-MS analysis. UV-Vis spectroscopic analysis of $G$. robusta leaf extract was performed at a wavelength of 200 to $800 \mathrm{~nm}$, and maximum absorption was observed at 208.94nm (2.33) and 282.97 (0.811). Similar absorption peaks were observed by Rani et al. [34] in the leaf extract of Meizotropis pellita. The nearest absorption spectra were also reported by Rajeshkumar and Jayaprakash [35] on selected red seaweed (Acanthophora specifera). FTIR analysis of extract was carried out by using Shimadzu ETIR spectrophotometer, and absorption spectra were recorded from 400 to $4000 \mathrm{~cm}^{-1}$. The results of FTIR analysis confirmed the presence of amines, alcohol, alkanes, nitriles, aldehyde, ether, and 1,2,4 trisubstituted and halo compounds at

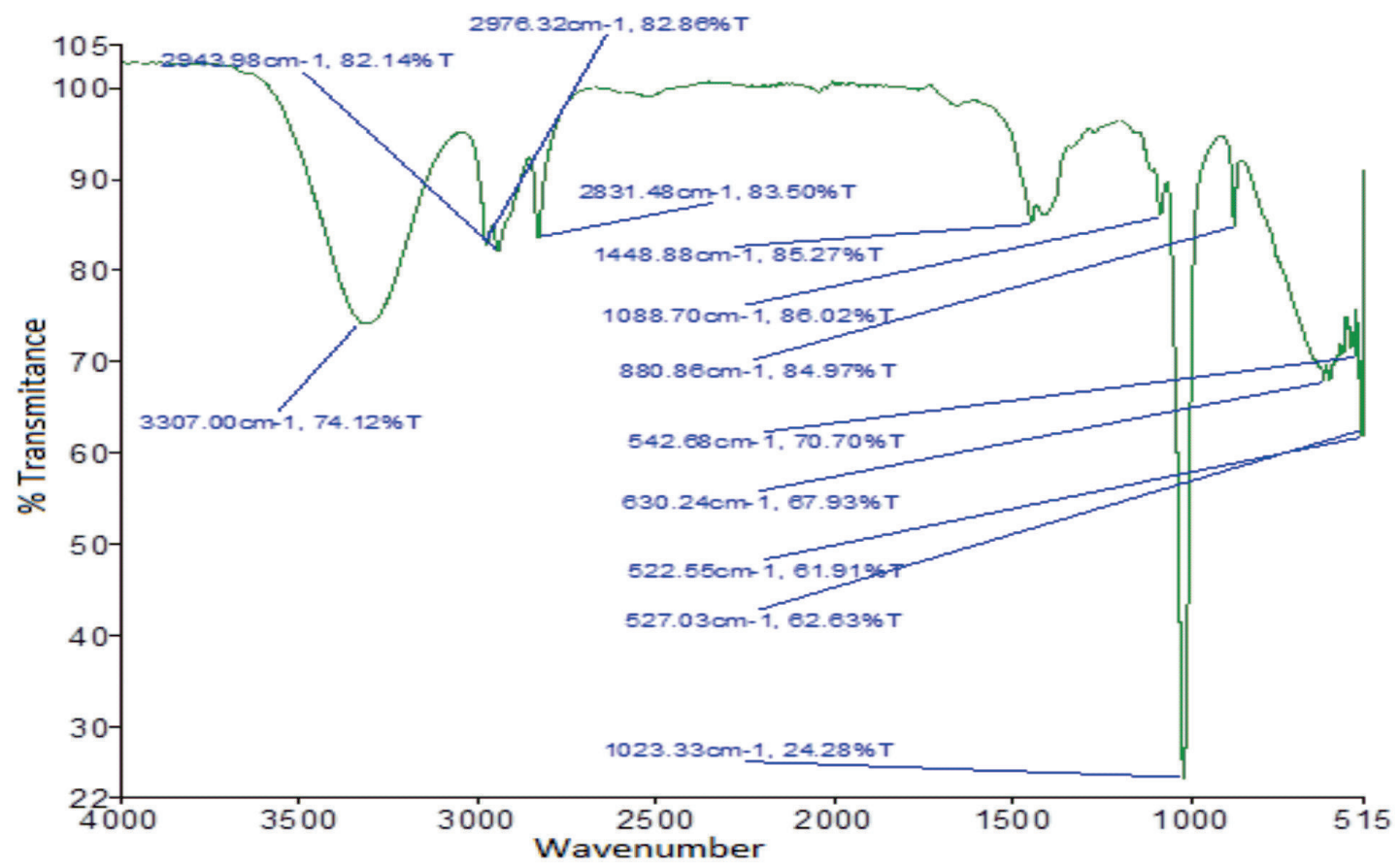

Fig. 9. FTIR spectrum of ethanolic leaf extract of G. robusta. 
Chromutogam ISB P(26-11-2018) C:ICCMS solution'DatalAZO DYESUZZ 2018UUGUST 2018USB P(26-11-2018).qgi

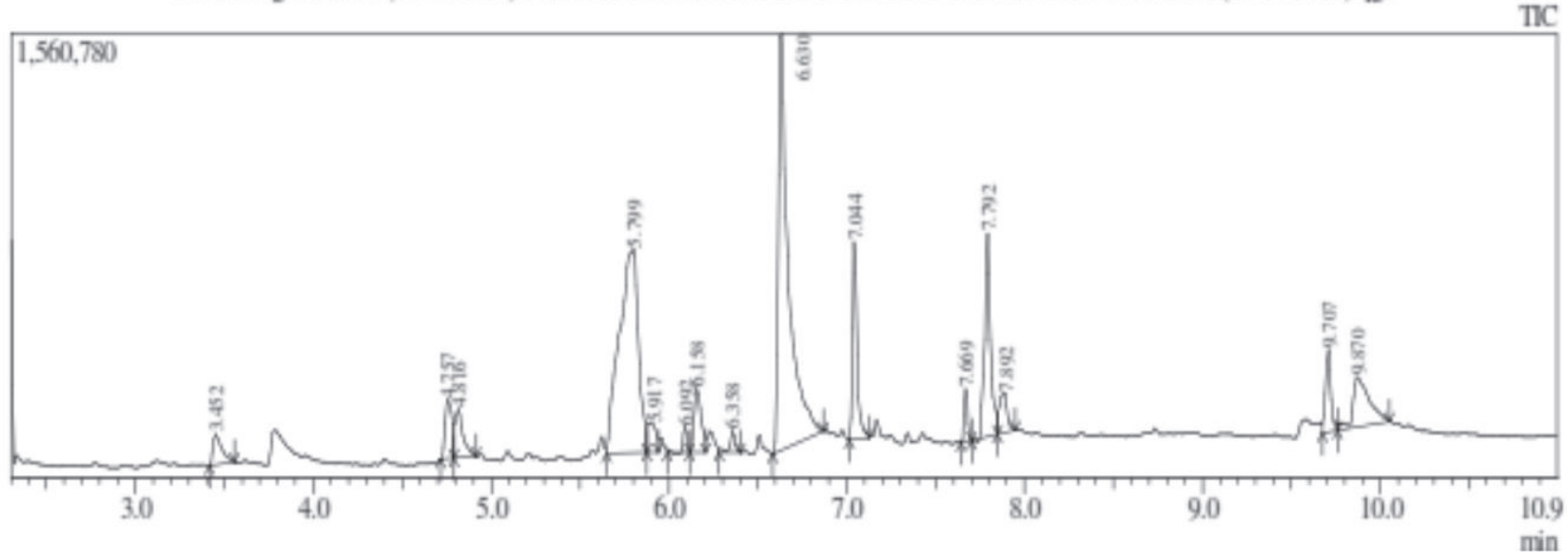

Fig. 10. GC-MS chromatogram of ethanolic leaves extract of G. robusta.

Table 6. Phytocomponents identified in ethanolic leaf extract of G. robusta by GC-MS peak report.

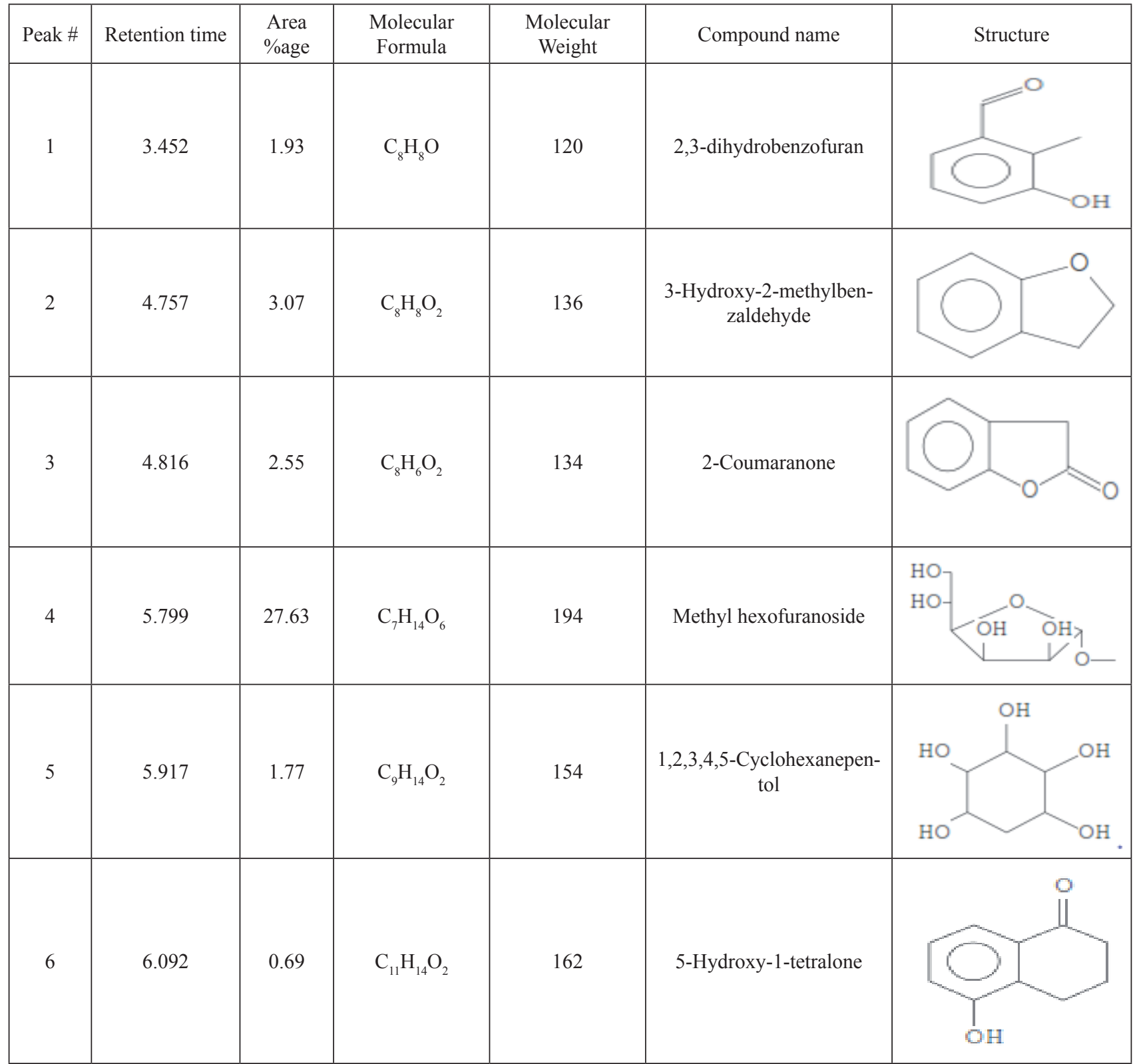


Table 6. Continued.

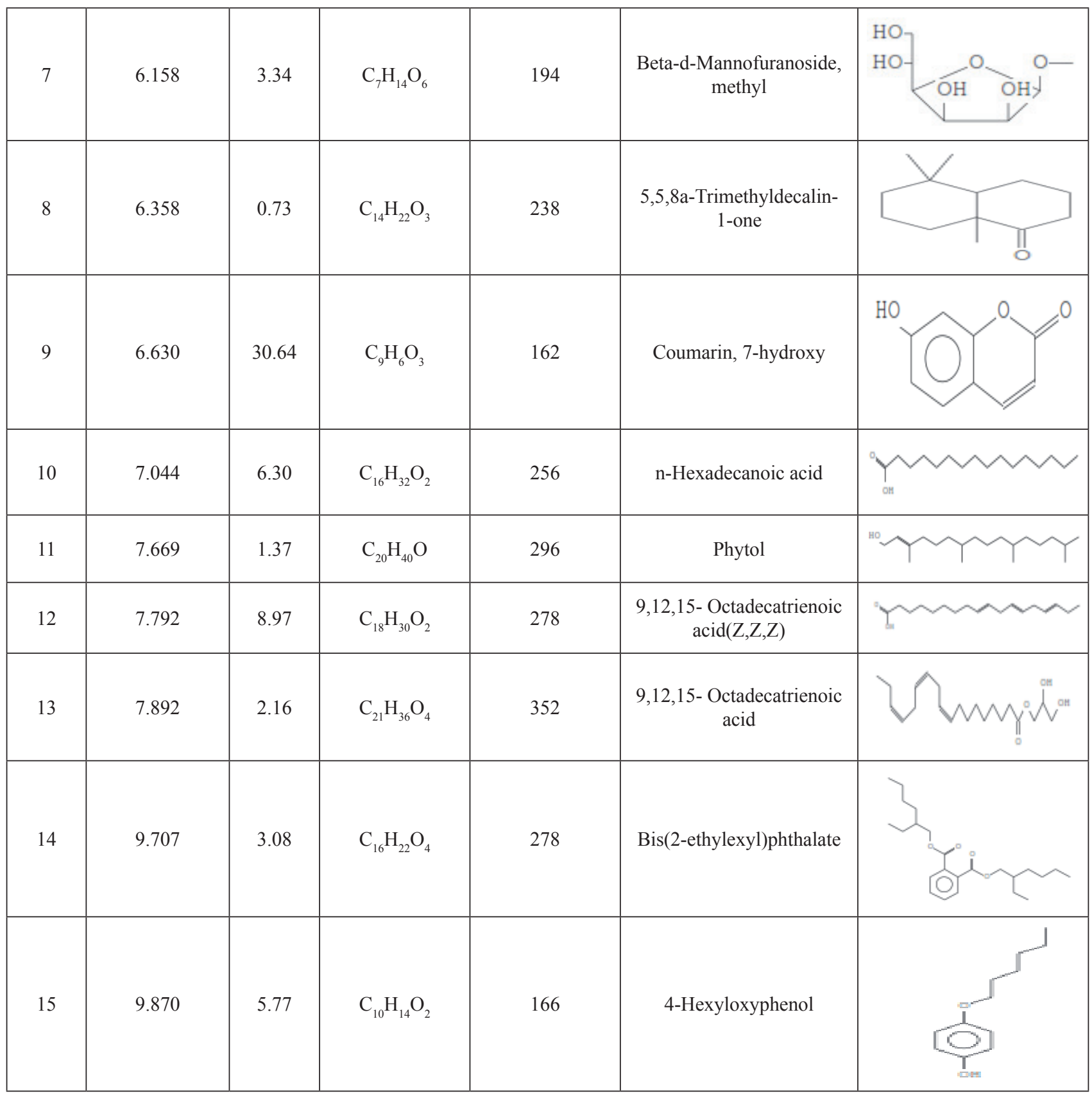

the wavelength of $3307.00,2976.32,2943.98,2831.48$, $1088.70,1023.33,880.88,630.24,542.66,527.03,522.55$ respectively. The presence of these functional groups in plant extracts has been confirmed by many studies previously [36, 37].

The GC-MS analysis of $G$. robusta leaf extracts characterized 15 phytochemicals by comparing their mass spectrum with the NIST library. Among the identified bioactive compounds, n-Hexadecanoic acid has been reported to have antimicrobial, antioxidant, antifibrinolytic, and hemolytic activity [38]. Similarly, n-Hexadecanoic acid, Phytol and 9,12,15- Octadecatrienoic acid(Z,Z,Z) characterized in $G$. robusta leaf extract has also been identified by Sermakkani and Thangapandian [39] in methanolic leaf extract of Cassia italica and reported their biological activities. n-Hexadecanoic acid (Palmitic acid) has an antiandrogenic, antioxidant, hypocholesterolemic, flavoring agent, nematicides, lubricant and pesticidal activities. Phytol belongs to Diterpenes and has anticancerous, anti-inflammatory, anti-microbial and antinociceptive activities [39, 40]. 9,12,15- Octadecatrienoic acid $(\mathrm{Z}, \mathrm{Z}, \mathrm{Z})$ is a fatty acid ester compound and has hepatoprotective, anti-inflammatory, insectifuge antihistaminic, 5-alpha-reductase inhibiting, antiandrogenic, pesticidal and cancer preventive activities [39, 41]. 2,3-Dihydrobenzofuran has been reported in Origanum vulgare seeds that have antimicrobial and anti-inflammatory activities [40]. In previous studies macrocyclic phenols, cinnamic acid 
derivatives and alkylresorcinols have been reported in G. robusta [42].

\section{Conclusions}

We have concluded from the present study that plant extracts could be an effective alternative for synthetic insecticides for the control of termites by targeting their hindgut endosymbionts. As bioactive insecticides, these plants contain phytochemical compounds that could be used in a refined form to synthesize bioactive preservatives that can be used to prevent infestation and damage caused by termites. Moreover, these plants are easily available and affordable in local areas of Pakistan. The phytochemical analysis of the most effective plant revealed that its leaves contain various valuable bioactive compounds that can be used as an alternative to synthetic insecticides. Further studies are required for isolation, identification and characterization of bioactive compounds from $G$. robusta leaves extract by column chromatography and their characterization by GCMS analysis for their application in industries.

\section{Acknowledgements}

A great thanks to the Higher Education Commission (HEC) of Pakistan for funding (Project no. 2291) and the Department of Animal Sciences, Quaid-i-Azam University Islamabad for providing laboratory facilities to carry out this research work.

\section{Conflict of Interest}

All the authors have approved the manuscript and declare no conflict of interest.

\section{References}

1. KUSWANTO E., AHMAD I., DUNGANI R. Threat of subterranean termites attack in the Asian countries and their control. A Review. Asian J. Appl. Sci. 8, 227, 2015.

2. BUCZKOWSKI G., BERTELSMEIER C. Invasive termites in a changing climate: A global perspective. Ecol. Evol. 7 (3), 974, 2017.

3. RUST M.K., SU N.Y. Managing social insects of urban importance. Annu. Rev. Entomol. 57, 355-, 2012.

4. PIMENTEL D., HEPPERLY P., HANSON J., DOUDS D., SEIDEL R. Environmental, energetic, and economic comparisons of organic and conventional farming systems. BioSci. 55 (7), 573, 2005.

5. LEE C.Y., VONGKALUANG C., LENZ M. Challenges to subterranean termite management of multi-genera faunas in Southeast Asia and Australia. Sociobiol. 50 (1), 213, 2007.
6. TASCIOGLU C., YALCIN M., DE TROYA T., SIVRIKAYA H. Termiticidal properties of some wood and bark extracts used as wood preservatives. BioRes. 7 (3), 2960, 2012.

7. ALSHEHRY A.Z., ZAITOUN A.A., ABO-HASSAN R.A. Insecticidal activities of some plant extracts against subterranean termites, Psammotermes hybostoma (Desneux) (Isoptera: Rhinotermitidae). J. Agri. Sci. 4, 257, 2014.

8. HASSAN B., MANKOWSKI M.E., KIRKER G., AHMED S. Effects of heartwood extractives on symbiotic protozoan communities and mortality in two termite species. Int. Biodeterior. Biodegradation. 123, 27, 2017.

9. FATIMA R., MORRELL J.J. Ability of plant-derived oils to inhibit dampwood termite (Zootermopsis augusticollis) activity. Maderas. Cienc. Tecnol. 17 (3), 685, 2017.

10. GONZALEZ-LAREDO R.F., CASTRO M.R., GUZMÁN NER., INFANTE J.A.G., MORENO-JIMÉNEZ M.R., KARCHESY J.J. Wood preservation using natural products. Madera. Bosques. 21, 63, 2015.

11. MOREIRA M.D., PICANÇO M.C., BARBOSA LCDA., GUEDES RNC. CAMPOS MRD., SILVA G.A., MARTINS J.C. Plant compounds insecticide activity against Coleoptera pests of stored products. Pesq. Agropec. Bras. 42 (7), 909, 2007.

12. ADEDEJI G.A., OGUNSANWO O.Y., ELUFIOYE T.O. Quantifications of phytochemicals and biocide actions of Lawsonia inermis linn. Extracts against wood termites and fungi. Int. Biodeterior. Biodegradation. 116, 155, 2017.

13. RASIB K.Z., ARIF., AIHETASHAM A., ALVI D.A. Bioactivity of some plant extracts against termite Odontotermes obesus (Rambur) (Blattodea: Termitidae). J. Biodivers. Biopros. Dev. 4, 167, 2017.

14. HASSAN B., MANKOWSKI M.E., KIRKER G.T., CLAUSEN C.A., AHMED S. Effects of White Mulberry (Morus alba) Heartwood Extract Against Reticulitermes flavipes (Blattodea: Rhinotermitidae). J. Econ. Entomol. 111 (3), 1337, 2018.

15. BASKARAN C., VELU S., KUMARAN K. The efficacy of Carica papaya leaf extract on some bacterial and a fungal strain by well diffusion method. Asian Pac. J. Trop. Dis. 2, 658, 2012.

16. SALARI M.H., AMINE G., SHIRAZI M.H., HAFEZI R., MOHAMMADYPOUR M. Antibacterial effects of Eucalyptus globulus leaf extract on pathogenic bacteria isolated from specimens of patients with respiratory tract disorders. Clin. Microbiol. Infect. 12 (2), 194, 2006.

17. MANZOOR F., MALIK SA., NAZ N., CHEEMA K.J., NAZ S. Potential of antitermitic activities of eucalyptus oil. Pak. J. Zool. 44 (2), 2012.

18. GHALEM B.R., MOHAMED B. Antibacterial activity of leaf essential oils of Eucalyptus globulus and Eucalyptus camaldulensis. Afr. J. Pharm. Pharmacol. 2 (10), 211, 2008.

19. SIRAMON P., OHTANI Y., ICHIURA H. Biological performance of Eucalyptus camaldulensis leaf oils from Thailand against the subterranean termite Coptotermes formosanus Shiraki. J. Wood. Sci. 55 (1), 41, 2009.

20. ELANGO G., RAHUMAN A.A., KAMARAJ C., BAGAVAN A., ZAHIR A.A., SANTHOSHKUMAR T., MARIMUTHU S., VELAYUTHAM K., JAYASEELAN C., KIRTHI A.V., RAJAKUMAR G. Efficacy of medicinal plant extracts against Formosan subterranean termite, Coptotermes formosanus. Ind. Crops. Prod. 36 (1), 524, 2012.

21. LEWIS JL., FORSCHLER BT. Impact of five commercial baits containing chitin synthesis inhibitors on the 
protist community in Reticulitermes flavipes (Isoptera: Rhinotermitidae). Environ. Entomol. 39 (1), 98, 2010.

22. TRIPATHY S., MIDDHA A., SWAIN S.R. Assessment of phytoconstituent of five faced Elaeocarpus ganitrus beads by FTIR and UV-VIS spectroscopic analysis. Imp. J. Interdiscip. Res. 2 (10), 2016

23. SAHU R., SAXENA J. Ultraviolet-Visible and Fourier Transform Infrared Spectroscopic Studies on NonConventional Species of Curcuma. Indian J. Adv. Chem. Sci. 2 (4), 300, 2014.

24. RUKSHANA M.S., DOSS A., KUMARI P.R. Phytochemical screening and GC-MS Analysis of leaf extract of Pergularia daemia (Forssk) Chiov. Asian J. Plant Sci. Res. 7, 9, 2017.

25. VENKATESWARA RAO J., PARVATHI K., KAVITHA P., JAKKA N.M., PALLELA R. Effect of chlorpyrifos and monocrotophos on locomotor behaviour and acetylcholinesterase activity of subterranean termites, Odontotermes obesus. Pest Manag. Sci. 61 (4), 417, 2005.

26. ABBAS M., SHAHID M., IQBAL M., ANJUM F., SHARIF S., AHMED S., PIRZADA T. Antitermitic activity and phytochemical analysis of fifteen medicinal plant seeds. J. Medi. Plants Res. 7 (22), 1608, 2013.

27. ACDA MN. Repellent effects of Annona crude seed extract on the Asian subterranean termite Coptotermes gestroi Wasmann (Isoptera: Rhinotermitidae). Sociobiol. 61 (3), 332, 2014.

28. BAKARUDDIN N.H., AB MAJID A.H. Efficacy of Several Plants Extracts on the Tunneling Activity and Survival of Subterranean Termites (Coptotermes gestroi and Globitermes sulphureus). Trop. Life Sci. Res. 30 (1), 33, 2019.

29. DOOLITTLE M., RAINA A., LAX A., BOOPATHY R. Effect of natural products on gut microbes in Formosan subterranean termite, Coptotermes formosanus. Int. Biodeterior. Biodegradation. 59 (1), 69, 2007.

30. MAISTRELLO L., HENDERSON G., LAINE RA. Comparative effects of vetiver oil, nootkatone and disodium octaborate tetrahydrate on Coptotermes formosanus and its symbiotic fauna. Pest Manag. Sci. 59 (1), 58, 2003.

31. AFZAL M., FARMAN M., RASIB KZ., QURESHI N.A. Biocidal action of silver oak (Grevillea robusta) leaf extract on the termite Heterotermes indicola Wasmann (Blattodea: Rhinotermitidae). Int. Biodeterior. Biodegradation. 139, 1, 2019.
32. RAJE K.R., HUGHES G.P., GONDHALEKAR A.D., GINZEL M.D., SCHARF M.E. Toxicity of turmeric extracts to the termite Reticulitermes flavipes (Blattodea: Rhinotermitidae). J. Econ. Entomol. 108 (4), 1479, 2015.

33. GOMATHI D., KALAISELVI M., RAVIKUMAR G., DEVAKI K., UMA C. GC-MS analysis of bioactive compounds from the whole plant ethanolic extract of Evolvulus alsinoides (L.) J. Food Sci. Technol. 52 (2), 1212, 2015.

34. RANI N., SHARMA S., SHARMA M. Phytochemical Analysis of Meizotropis pellita by FTIR and UV-VIS Spectrophotometer. Indian. J Sci. Technol. 9 (31), 2016.

35. RAJESHKUMAR R., JAYAPRAKASH K. Screening of UV-VIS, TLC and FTIR spectroscopic studies on selected red seaweed (Acanthophora specifera) collected from Gulf of Mannar, Tamilnadu, India. World. J. Pharm. Sci. 4 (10), 28, 2016.

36. ASHOKKUMAR R., RAMASWAMY M. Phytochemical screening by FTIR spectroscopic analysis of leaf extracts of selected Indian Medicinal plants. I.J.C.M.A.S. 3 (1), 395, 2014.

37. PACKIALAKSHMI N., NAZIYA S. Fourier transform infrared spectroscopy analysis of various solvent extracts of Caralluma fimbriyata. Asian. J. Biomed. Pharm. Sci. 4 (36), 2014.

38. NITHYADEVI J., SIVAKUMAR R. Phytochemical Screening and GC-MS, FT-IR Analysis of Methanolic Extract Leaves of Solanum torvum Sw. Int. J. Res. Stud. Biosci. 3 (9), 61, 2015.

39. SERMAKKANI M., THANGAPANDIAN V. GC-MS analysis of Cassia italica leaf methanol extract. Asian. J. Pharm. Clin. Res. 5 (2), 90, 2012.

40. AL-TAMEME H.J., HAMEED I.H., IDAN S.A., HADI M.Y. Biochemical analysis of Origanum vulgare seeds by fourier-transform infrared (FT-IR) spectroscopy and gas chromatography mass spectrometry (GC-MS). J. Pharmacognosy. Phytother. 7 (9), 221, 2015.

41. KADHIM M.J., SOSA A.A., HAMEED I.H. Evaluation of anti-bacterial activity and bioactive chemical analysis of Ocimum basilicum using Fourier transform infrared (FTIR) and gas chromatography-mass spectrometry (GC-MS) techniques. J. Pharmacognosy. Phytother. 8 (6), 127, 2016.

42. CHUANG T.H., CHAN H.H., WU T.S., LI C.F. Chemical Constituents and Biological Studies of the Leaves of Grevillea robusta. Molecules. 16, 9331, 2011. 